\title{
Clonal Diversity, Low-Level and Heterogeneous Oxacillin Resistance of Oxacillin Sensitive MRSA
}

This article was published in the following Dove Press journal:

Infection and Drug Resistance

\author{
Roushan Liu',* \\ Jian Zhang ${ }^{2, *}$ \\ Xiaoli $\mathrm{Du}^{3}$ \\ Yingying $L^{\prime}$ \\ Xiangyu Gao' \\ Yanyan Wang' \\ Junrui Wang'
}

'Department of Laboratory Medicine, Affiliated Hospital of Inner Mongolian Medical University, Hohhot, OI0050,

People's Republic of China; ${ }^{2}$ Department of Laboratory Medicine, Bayannur People's Hospital, Bayannur City, 015000 , People's Republic of China; ${ }^{3}$ National Institute for Communicable Disease Control and Prevention, Chinese Center for Disease Control and Prevention, Beijing, 102206, People's Republic of China

*These authors contributed equally to this work
Correspondence: Junrui Wang Department of Laboratory Medicine, Affiliated Hospital of Inner Mongolian Medical University, Hohhot, 010050,

People's Republic of China

Tel +86 I3347I04892

Email wangjunruil23@yeah.net
Purpose: This study investigates the phenotypic and genotypic resistance features of OSMRSA clinical isolates and their distinctive sensitivities to oxacillin.

Methods: 1200 clinical isolates of Staphylococcus aureus were enrolled in this study. Automated antibiotics susceptibility tests on VITEK-2 and BD Phoenix-100 ${ }^{\mathrm{TM}}$, cefoxitin disc diffusion method, oxacillin broth microdilution method, mecA, and mecC gene detection were performed to identify OS-MRSA. MLST, PFGE, SCCmec, and spa typing methods were employed to determine genotypes of OS-MRSA isolates. Heterogeneous resistance of OS-MRSA isolates was detected using the population analysis profiling method, and PBP2a latex agglutination assay was used to detect the expression of PBP2a protein for 14 OSMRSA isolates and their highly resistant subpopulations.

Results: A total of 14 OS-MRSA isolates $(1.17 \%, 14 / 1200)$ were identified, and all of the isolates were confirmed to be positive with the mecA gene and negative with the mecC gene. All of the 14 OS-MRSA isolates were identified as MSSA by VITEK-2, BD Phonenix-100, and oxacillin broth microdilution methods, while $21.43 \%(3 / 14)$ isolates were determined to be MRSA by the cefoxitin disk diffusion method. Genotypes of the 14 OS-MRSA isolates were diverse, and no dominant clones were identified. The prevalence of $p v l$ gene among 14 OS-MRSA isolates was high up to $64.29 \%(9 / 14)$. All of the isolates showed heterogeneous resistance to oxacillin, while frequencies of the oxacillin-resistant subpopulations ranged from $10^{-9}$ to $10^{-5}$ and differed significantly among different isolates.

Conclusion: The overall prevalence of OS-MRSA was relatively lower, but lower oxacillin MICs, low testing sensitivity of routine antibiotics susceptibility testing methods and weak PBP2a protein expression were observed in this study. 14 OS-MRSA showed diverse genotypes and universal heterogeneous resistance, and inaccurate laboratory identification and improper antimicrobial usage may promote the induction of highly resistant subpopulations and lead to treatment failure.

Keywords: oxacillin sensitive MRSA, molecular typing, heterogeneous resistance

\section{Introduction}

Methicillin-resistant Staphylococcus aureus (MRSA) is an important bacterial pathogen, leading to multiple kinds of invasive infections and increasing mortality of inpatients. ${ }^{1}$ The primary resistance mechanism of MRSA is mediated by the expression of a modified penicillin-binding protein $2 \mathrm{a}$ (PBP2a), which was encoded by the mecA gene. ${ }^{2,3}$ Recently, a new issue, rarely reported previously, was the misidentification of MRSA in clinical laboratories, which was mainly owing to oxacillin susceptible mecA positive Staphylococcus aureus (OS-MRSA) emerged in several areas around the globe. ${ }^{4-6}$ 
It is well known that the detection of resistance phenotypes with antibiotics susceptibility testing methods was routinely performed in most clinical laboratories. By contrast, widespread usage of genotypic methods was problematic. Since OS-MRSA isolates often showed lower oxacillin MICs (typically $\leq 2 \mu \mathrm{g} / \mathrm{mL}$ ), these isolates were often mistakenly identified as methicillin-susceptible Staphylococcus aureus (MSSA) with phenotypic methods, and even the isolates may become highly resistant ones when exposed to $\beta$-lactams antibiotics or mupirocin., ${ }^{7,8}$ Therefore, to discriminate OS-MRSA isolates, other alternative methods are required to minimize the error caused by traditional phenotypic techniques. The mecA gene detection or PBP2a protein agglutination assay was the most frequently suggested methods to complement conventional phenotypic methods. However, the discrepancies between the mecA gene and PBP2a protein expressions were observed, and a novel mecA homologue $(m e c C)$ was not detectable by PBP2a agglutination tests. ${ }^{9,10}$ Therefore, a combination of phenotypic and genotypic methods simultaneously is strongly suggested for the accurate identification of OS-MRSA. ${ }^{5}$

Moreover, heterogeneous resistance was reported to be a universal phenomenon among OS-MRSA isolates collected in Africa. ${ }^{8}$ It may pose a more knotty issue for clinicians when $\beta$-lactam antibiotics were prescribed to treat infections caused by OS-MRSA or even lead to treatment failure. ${ }^{11}$ However, characterization of heterogeneous resistance was not reported in other areas as far as I know. The actual existence of heterogeneous resistance among isolates from different groups of patients needs to be further investigated.

This study aims to investigate the phenotypic and genotypic characteristics of OS-MRSA strains isolated from patients admitted to two tertiary teaching hospitals in China. The heterogeneous resistance and its potential clinical significance were further explored.

\section{Materials and Methods Ethics Approval}

This study is exempt from formal ethical approval and informed consent according to the local ethical guidelines, and the statement of exempt from ethical approval was provided by Ethics committee of Affiliated hospital of Inner Mongolian medical university (Reference number KY2020029), since no samples were specifically collected for this research, and the data analysis was analyzed anonymously.

\section{Collection and Identification of Isolates}

One thousand two hundred clinical isolates of $S$. aureus were collected at Affiliated hospital of Inner Mongolian Medical University and Bayannur people's hospital from January 2011 to March 2019. All of the isolates were isolated from routine clinical samples and the isolates were frozen at $-80^{\circ} \mathrm{C}$. The isolates were retrospectively identified as MSSA with AST-GP67 card on VITEK-2 compact automation equipment (BioMérieux, France). The isolates were sub-cultured on blood agar plates during this study, and all of them were re-validated by MALDITOF MS equipment (micro-typer MS, Tianrui, China) as well as $16 \mathrm{~S}$ rRNA gene sequencing.

\section{mecA, mecC, and pvl Gene Detection}

Generally, bacterial precipitate for each isolate was digested with lysostaphin $(1 \mathrm{mg} / \mathrm{mL})$ (Merck, USA) at $37^{\circ} \mathrm{C}$ for $30 \mathrm{~min}$, and then the bacterial chromosomal DNA was extracted based on the TIANamp Bacterial DNA kit (Tiangen Biotech, China). $16 S$ rRNA gene, $m e c A$ gene, $m e c C$ gene, and $p v l$ gene for all 1200 isolates were amplified, and PCR conditions were set according to the procedure described previously. ${ }^{12-16}$ The primers used in this study are presented in Table 1. S. aureus ATCC25923 and ATCC43300 reference strains were used as control.

\section{Antibiotics Susceptibility Testing}

Phenotypic methods were used to detect their resistance levels to oxacillin or cefoxitin in the isolates positive with the mecA or mecC gene expression. The methods comprise of AST-GP67 card on VITEK-2 fully automated equipment (BioMérieux, France), BD Phoenix ${ }^{\mathrm{TM}}$ PMIC/ID panel on BD Phonenix-100 equipment (BD, Sparks, MD, USA), cefoxitin disc diffusion method as well as oxacillin microdilution broth method based on the procedure recommended by CLSI M100 (29th edition). ${ }^{17}$

\section{Molecular Typing}

Pulsed-Field Gel Electrophoresis (PFGE)

The bacterial density of the tested isolates was adjusted to $3.5 \sim 4.0 \mathrm{Mcf}$ and was digested with lysostaphin (1 mg/ $\mathrm{mL}$ ) (Merck, USA) at $37^{\circ} \mathrm{C}$ for $30 \mathrm{~min}$. Bacterial chromosomal DNA of $S$. aureus isolates was prepared from all the isolates and cleaved with 40U SmaI (Takara, China). 
Table I Primers for PCR Amplification in This Study

\begin{tabular}{|c|c|c|}
\hline Primers & Sequences (5'-3') & Size (bp) \\
\hline I6S rRNA-F & GTAGGTGGCAAGCGTTATCC & $228^{12}$ \\
\hline I6S rRNA-R & CGCACATCAGCGTCAG & \\
\hline mecA-F & TCCAGATTACAACTTCACCAGG & $162^{13}$ \\
\hline mecA-R & ССАСТTCATATCTTGTAACG & \\
\hline mecC-F & GAAAAAAAGGCTTAGAACGCCTC & $718^{14}$ \\
\hline $\operatorname{mec} C-\mathrm{R}$ & GAAGATCTTTTCCGTTTTCAGC & \\
\hline pvl-F & ATCATTAGGTAAAATGTCTGGACATGATCCA & $433^{15}$ \\
\hline pvl-R & GCATCAASTGTATTGGATAGCAAAAGC & \\
\hline Spa-III $3 f$ & TAA AGACGATCCTTCGGTGAGC & Variable $^{16}$ \\
\hline Spa-I5I4r & CAGCAGTAGTGCCGTTTGCT & \\
\hline
\end{tabular}

Meanwhile, the standard strain of S. Braenderup H9812 was prepared using 40U XbaI (Takara, China) and was used as the standard molecular mass. Electrophoresis was performed on $1 \%$ agarose gels (Lonza, Rockland, ME, USA) in $0.5 \mathrm{M}$ Tris/borate/EDTA buffer on a CHEFMapper XA PFGE system (Bio-Rad, Hercules, CA, USA). The gel was stained with ethidium bromide $(0.5$ $\mu \mathrm{g} / \mathrm{mL}$ ) and photographed under the GelDoc XR system (Bio-Rad, Hercules, CA, USA). PFGE profiles were analyzed by Bionumerics v7.6 software.

Multi-Locus Sequence Typing (MLST) and Spa Typing The experiment was performed as follows. Generally, the bacterial chromosomal DNA was extracted based on the instruction of the TIANamp Bacterial DNA kit (Tiangen Biotech, China). PCRs were carried out with $30-\mu \mathrm{L}$ reaction volumes containing $0.3 \mu \mathrm{L}$ of chromosomal DNA (approximately $0.3 \mu \mathrm{g}), 1 \mu \mathrm{g}$ of each primer as well as Taq DNA polymerase mixture supplied by Taq PCR MasterMix kit (Tiangen Biotech, China). The PCR reaction conditions were set as described by Enright et al. ${ }^{18}$ Seven respective PCR assays were conducted to amplify seven housekeeping genes for S.aureus, including arc, aroE, glpF, gmk, pta, tpi and yqil. The PCR products were sequenced with the same primers as those used in PCR amplification and Sanger sequencing was performed on ABI 3730XL DNA Analyzer (Applied Biosystems, USA). The sequences were compared with the known alleles in the MLST database (http://saureus.mlst.net). The variable repeat region of the spa was amplified with the following primers, Spa1113f (TAAAGACGATCCTTCGGTGAGC) and Spa1514r (CAGCAGTAGTGCCGTTTGCT), ${ }^{16}$ and the PCR products were sequenced on ABI 3730XL DNA Analyzer (Applied Biosystems, USA), and the sequences were analyzed using the Random web server (http://spaserver.ridom. de). The typing of chromosomal cassette mec ( $\mathrm{SCCmec}$ ) for $S$. aureus isolates was carried out based on the well-known protocol, ${ }^{19}$ and the unique types were designated. The standard SCCmec typing strains (NCTC10042, type I SCCmec; N315, type II SCCmec; 85/2080, type III SCCmec; JCSC4744, type IV SCCmec; HS663, type V SCCmec) were used as controls.

\section{Population Analysis Profiling (PAP)}

According to the procedure introduced previously, ${ }^{20}$ the PAP assay was performed as follows. The isolates were cultured with shaking in Tryptic Soy Broth (TSB) at $35^{\circ} \mathrm{C}$, and overnight cultures were centrifuged and diluted to a suitable density. The diluted cultures were plated onto Tryptic Soy Agar (TSA) plates at a density of $10^{9} \mathrm{CFU} /$ plate. The TSA plates were prepared with serial concentrations of oxacillin $(0.06-800 \mu \mathrm{g} / \mathrm{mL})$ with or without $0.03 \mu \mathrm{g} / \mathrm{mL}$ mupirocin. The plates were then incubated at $35^{\circ} \mathrm{C}$ for 48 hours at aerobic condition, and the number of colonies on each plate was counted, and the frequency of highly resistant subpopulations was calculated.

\section{PBP2a Protein Detection}

The PBP2a protein expression for 14 OS-MRSA isolates and their corresponding high-level resistant subpopulations were detected with the following procedure. Generally, approximately $10^{9} \mathrm{CFU}$ of the tested isolates were collected in an eppendorf tube and centrifuged at 10,000 rpm for 10 min, and the bacterial precipitate was collected. The 
Table 2 Antimicrobial Susceptibility Features of 14 OS-MRSA Isolates

\begin{tabular}{|c|c|c|c|c|c|c|c|c|c|c|c|c|}
\hline Isolates & PEN & ERY & TCY & CLI & GEN & LVX & SXT & NIT & VAN & LNZ & RIF & DAP \\
\hline OS-200 & $\mathrm{R}$ & $\mathrm{R}$ & $\mathrm{R}$ & $S$ & $S$ & $S$ & $S$ & $S$ & $S$ & S & $S$ & $S$ \\
\hline OS-253 & $\mathrm{R}$ & $\mathrm{R}$ & $\mathrm{R}$ & $S$ & S & $S$ & $S$ & $S$ & $S$ & $S$ & $S$ & $S$ \\
\hline OS-373 & $R$ & $\mathrm{R}$ & 1 & $R$ & $S$ & $S$ & $S$ & $S$ & $S$ & $S$ & $S$ & $S$ \\
\hline OS-5II & $R$ & $\mathrm{R}$ & $R$ & $S$ & S & S & $S$ & $S$ & S & $S$ & S & $S$ \\
\hline OS-678 & $R$ & I & $\mathrm{R}$ & $S$ & $S$ & $\mathrm{R}$ & $S$ & $S$ & $S$ & $S$ & $S$ & $S$ \\
\hline OS-682 & $R$ & $\mathrm{R}$ & $\mathrm{R}$ & $\mathrm{R}$ & $\mathrm{R}$ & $S$ & $R$ & $S$ & $S$ & $S$ & $S$ & $S$ \\
\hline OS-790 & $R$ & $\mathrm{R}$ & $\mathrm{R}$ & $\mathrm{R}$ & $S$ & $S$ & $S$ & S & $S$ & S & S & $S$ \\
\hline OS- 1050 & $R$ & $\mathrm{R}$ & $\mathrm{R}$ & $\mathrm{R}$ & $\mathrm{R}$ & $S$ & $S$ & $S$ & $S$ & $S$ & $S$ & $S$ \\
\hline OS- 1057 & $R$ & $\mathrm{R}$ & $S$ & $S$ & $S$ & $S$ & $S$ & $S$ & $S$ & $S$ & $S$ & $S$ \\
\hline OS-1059 & $R$ & $\mathrm{R}$ & $\mathrm{R}$ & $S$ & S & S & $S$ & $S$ & S & $S$ & $S$ & $S$ \\
\hline OS- 1060 & $\mathrm{R}$ & I & $S$ & I & S & $S$ & $S$ & $S$ & $S$ & $S$ & $S$ & $S$ \\
\hline OS-106I & $R$ & $\mathrm{R}$ & $S$ & $\mathrm{R}$ & S & S & $S$ & $S$ & S & S & S & $S$ \\
\hline OS- 1068 & $R$ & $\mathrm{R}$ & 1 & $\mathrm{~S}$ & $\mathrm{~S}$ & S & S & S & $S$ & $S$ & S & $S$ \\
\hline OS-1502 & $\mathrm{R}$ & 1 & $\mathrm{R}$ & $\mathrm{S}$ & $\mathrm{R}$ & $\mathrm{S}$ & $\mathrm{S}$ & S & $S$ & S & S & S \\
\hline Resistant rates (\%) & 100 & 78.57 & 64.29 & 35.71 & 21.43 & 7.14 & 7.14 & 0 & 0 & 0 & 0 & 0 \\
\hline
\end{tabular}

Abbreviations: PEN, penicillin; ERY, erythromycin; TCY, tetracycline; CLI, clindamycin; Gen, gentamicin; LVX, levofloxacin; SXT, trimethoprim-sulfamethoxazole; NIT, nitrofurantoin; VAN, vancomycin; LNZ, linezolid; RIF, rifampicin; DAP, daptomycin; S, sensitive; I, intermediate; R, resistant.

precipitate was then incubated for $5 \mathrm{~min}$ at $100^{\circ} \mathrm{C}$ and the mixture of bacterial protein was extracted. An agglutination test was then carried out based on the instructions of the PBP2a agglutination test kit (Oxoid Limited, US). S. aureus ATCC 25923 and ATCC43300 reference strains were used as negative and positive controls, respectively.

\section{Results}

Among $1200 \mathrm{~S}$. aureus isolates tested in this study, 14 OSMRSA isolates (1.17\%) were identified, and all of them were the mecA gene positive and negative with the mecC gene. Most of the OS-MRSA isolates $(64.29 \%, n=9)$ were isolated from wound samples, followed by pus samples $(14.29 \%, \mathrm{n}=2)$, whole blood sample $(7.14 \%, \mathrm{n}=1)$, BALF sample $(7.14 \%, \mathrm{n}=1)$ and sputum sample $(7.14 \%, \mathrm{n}=1)$. All of the isolates were isolated from inpatients, and the average age of the patients were 36.7 years old $(8 \sim 57$ years). Two isolates (OS-200 and OS-1068) of OS-MRSA were isolated from pediatric patients $(14.29 \%, 2 / 14)$.

The resistance rates of the 14 OS-MRSA isolates to penicillin, erythromycin, tetracycline, clindamycin, gentamicin, levofloxacin and trimethoprim-sulfamethoxazole (SXT) were 100\%, 78.57\%, 64.29\%, 35.71\%, 21.43\%, $7.14 \%$, and 7.14\%, respectively. All 14 OS-MRSA isolates were sensitive to nitrofurantoin, vancomycin, linezolid, rifampicin, and daptomycin, as shown in Table 2.

Furthermore, different phenotypic methods were assessed in differentiating OS-MRSA isolates. Oxacillin MICs detected by VITEK-2 oxacillin and BD phoenix-100 showed good agreement with those detected by the oxacillin broth microdilution method. Unfortunately, all of the 14-OS MRSA isolates were mistakenly identified to be MSSA by VITEK-2, BD phoenix-100, and oxacillin broth microdilution methods, as shown in Table 3. Three out of 14 OS-MRSA isolates were determined to be MRSA by cefoxitin disk diffusion method, the oxacillin MICs of which were $1 \mu \mathrm{g} / \mathrm{mL}$ (OS-1068 and OS-1502) and $0.5 \mu \mathrm{g} / \mathrm{mL}$ (OS-200), respectively. Moreover, lower expression of PBP2a protein was observed in these 14 OSMRSA isolates and only $42.86 \%(6 / 14)$ showed a positive reaction with agglutination assay (Table 3 ). The correlation between levels of oxacillin MIC and expression level of PBP2a protein was not observed.

MLST and spa types of the 14 OS-MRSA isolates showed a diverse tendency, only ST22-t309 types accounted for $14.29 \%(2 / 14)$ and both of them were not typeable with the SCCmec typing method. Besides, ST398, ST59, ST25 accounted for $42.86 \%(6 / 14)$ and $14.29 \%(2 / 14)$ for each ST type, respectively. Except for OS-200, OS-790, and OS-373 isolates, ten out of 14 isolates belonged to the SCCmec IV type, while only one isolate (OS-678) was categorized as SCCmec I type (Figure 1). Furthermore, the prevalence of the $p v l$ gene among 14 OS-MRSA isolates was high up to $64.29 \%(9 / 14)$, while that of $1200 \mathrm{~S}$. aureus isolates was $25.5 \%(306 / 1200)$.

All OS-MRSA isolates presented with heterogeneous resistance, while frequencies of highly resistant subpopulations varied from $10^{-9}$ to $10^{-5}$ among different 
Table 3 Phenotypic Resistance Features of 14 OS-MRSA Isolates with Different Methods

\begin{tabular}{|c|c|c|c|c|c|c|c|}
\hline Isolates & $\begin{array}{c}\text { VITEK-2 } \\
\text { Oxacillin }(\mu \mathrm{g} / \\
\mathrm{mL})\end{array}$ & $\begin{array}{c}\text { VITEK-2 } \\
\text { Cefoxitin Screen } \\
(+/-)\end{array}$ & $\begin{array}{c}\text { BD Phoenix } \\
\text { Oxacillin } \\
(\mu \mathrm{g} / \mathrm{mL})\end{array}$ & $\begin{array}{l}\text { BD Phoenix } \\
\text { Cefoxitin } \\
(\mu \mathrm{g} / \mathrm{mL})\end{array}$ & $\begin{array}{l}\text { Cefoxitin Disc } \\
\text { Diffusion }(\mathrm{mm})\end{array}$ & $\begin{array}{l}\text { Oxacillin Broth } \\
\text { Microdilution } \\
(\mu \mathrm{g} / \mathrm{mL})\end{array}$ & $\begin{array}{c}\text { PBP2a } \\
\text { Protein }\end{array}$ \\
\hline OS-200 & 0.5 & - & I & 4 & 21 & I & - \\
\hline OS-253 & 2 & - & I & 4 & 23 & 1 & + \\
\hline OS-373 & $\leq 0.25$ & - & $\leq 0.25$ & $\leq 2$ & 22 & 0.25 & - \\
\hline OS-5II & $\leq 0.25$ & - & 0.5 & $\leq 2$ & 24 & 0.5 & + \\
\hline OS-678 & I & - & 0.5 & 4 & 23 & 0.5 & + \\
\hline OS-682 & 2 & - & 1 & 4 & 26 & 0.5 & - \\
\hline OS-790 & $\leq 0.25$ & - & 0.5 & $\leq 2$ & 24 & 0.25 & - \\
\hline OS- 1050 & $\leq 0.25$ & - & $\leq 0.25$ & 4 & 27 & 0.25 & + \\
\hline OS- 1057 & 1 & - & 0.5 & 4 & 26 & 0.5 & + \\
\hline OS- 1059 & 0.5 & - & 1 & 4 & 24 & 0.25 & - \\
\hline OS- 1060 & $\leq 0.25$ & - & $\leq 0.25$ & $\leq 2$ & 30 & 0.25 & - \\
\hline OS-106I & 0.5 & - & I & 4 & 24 & 0.5 & - \\
\hline OS- 1068 & 1 & - & I & 4 & 19 & 1 & - \\
\hline OS-I502 & 1 & - & 1 & 4 & 21 & 0.5 & + \\
\hline
\end{tabular}

isolates. For each isolate, the MICs of the highly resistant subpopulations to oxacillin increased at least 16 folds compared with that of the primary isolate, and those of the four isolates (OS-682, OS-1059, OS-1060, OS-1502) increased up to 1024 folds. The effects in the induction of resistance by $0.03 \mu \mathrm{g} / \mathrm{mL}$ mupirocin were observed in $71.43 \%(10 / 14)$ isolates, while one out of them showed a significant inhibition effect (OS-1502). With PAP assay, the frequencies and resistance levels of the subpopulations with the highest resistant levels to oxacillin for each isolate differed significantly, and the oxacillin MICs of the most highly resistant subpopulations originated from $57.14 \%(8 / 14)$ isolates exceeded $100 \mu \mathrm{g} / \mathrm{mL}$ (Figure 2). It is noteworthy that all of the highly resistant subpopulations were positive with PBP2a protein expression, as shown in Table 4.

\section{Discussion}

As a particular subset of MRSA, the clonal distribution and prevalence rates of OS-MRSA varied greatly from $1.25 \%$ to $52 \%$ among different reports. ${ }^{6,7,21}$ The prevalence rate found in this study is $1.17 \%$ in this study, which is similar to those reported in two previous studies in China. $^{7,22}$ The number of $S$. aureus isolates investigated in different studies may be a primary reason for significant variation of prevalence rates among different reports. Moreover, the 14 OS-MRSA isolates were all sensitive to both oxacillin and cefoxitin, no oxacillin susceptible but cefoxitin-resistant isolate was enrolled in this study. More multi-center investigations need to be further carried out to get knowledge of the actual prevalence of OSMRSA. In consistent with some previous studies, ${ }^{7,8}$ most of the OS-MRSA isolates investigated in this study
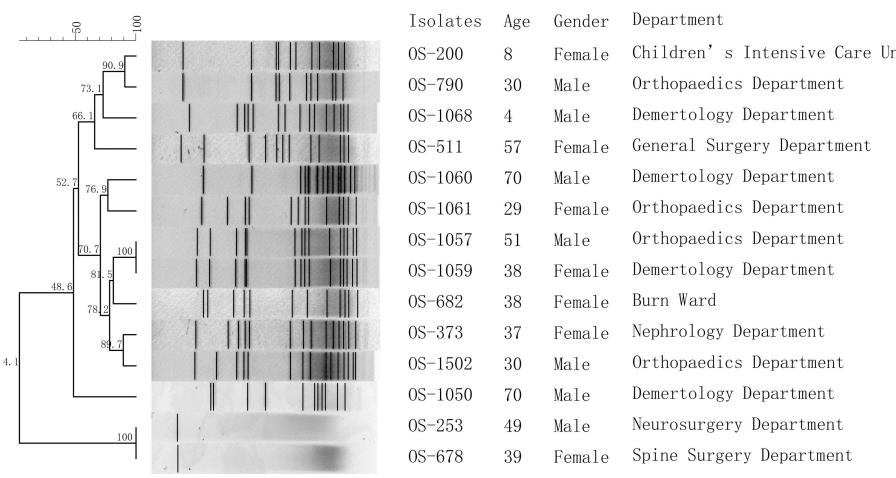

$\begin{array}{ll}\text { IsolateDate } & \text { Type of samples } \\ 2016-03-31 & \text { BALF } \\ 2016-07-06 & \text { Wound } \\ 2012-11-19 & \text { Pus } \\ 2017-05-10 & \text { Pus } \\ 2011-10-19 & \text { Wound } \\ 2011-08-30 & \text { Wound } \\ 2011-12-26 & \text { Wound } \\ 2012-04-21 & \text { Wound } \\ 2019-06-13 & \text { Wound } \\ 2016-05-23 & \text { Blood } \\ 2017-06-19 & \text { Wound } \\ 2013-01-16 & \text { Sputum } \\ 2011-08-11 & \text { Wound } \\ 2019-05-23 & \text { Wound }\end{array}$

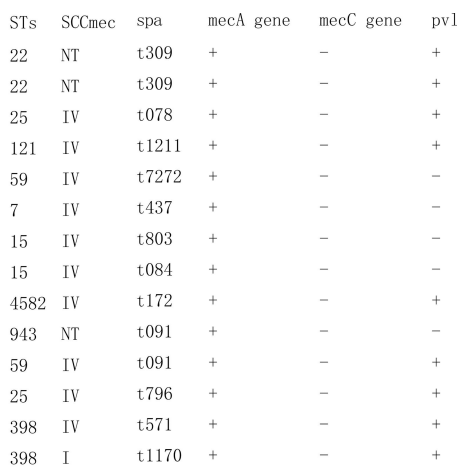

Figure I Molecular typing results of 14 OS-MRSA isolates.

Abbreviations: BALF, bronchoalveolar lavage fluid; NT, not typeable. 


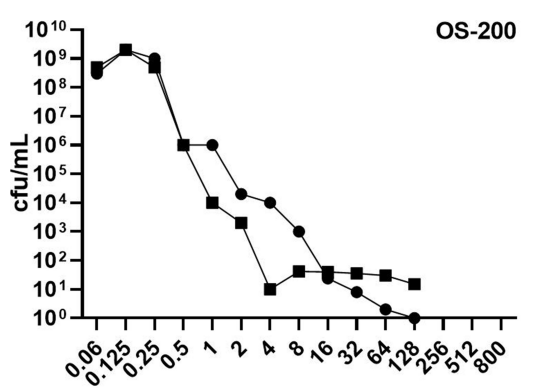

Oxacillin $(\mu \mathrm{g} / \mathrm{mL})$
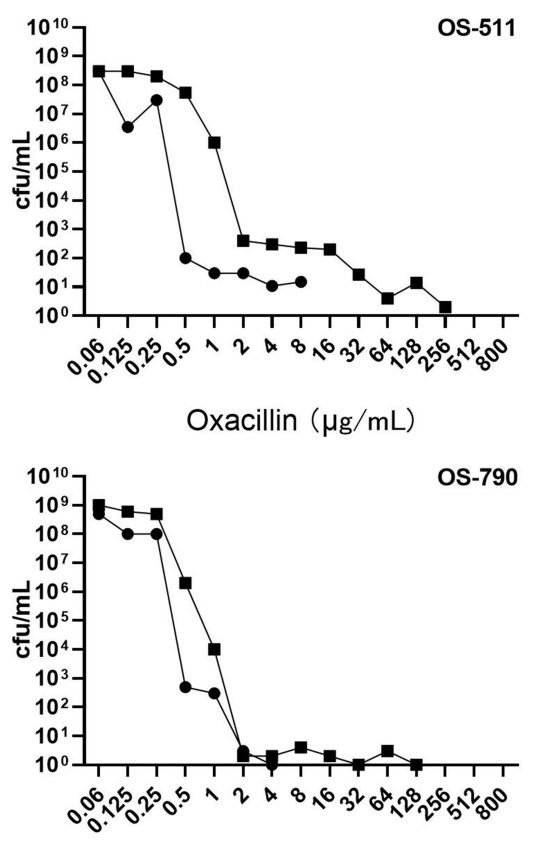

Oxacillin $(\mu \mathrm{g} / \mathrm{mL})$

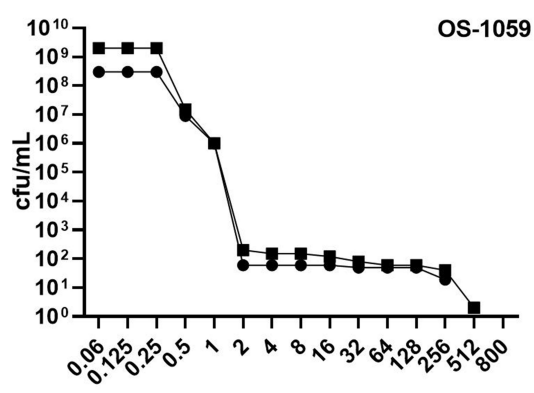

Oxacillin $(\mu \mathrm{g} / \mathrm{mL})$

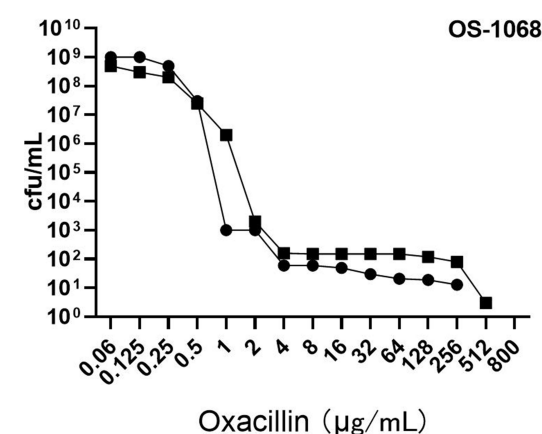

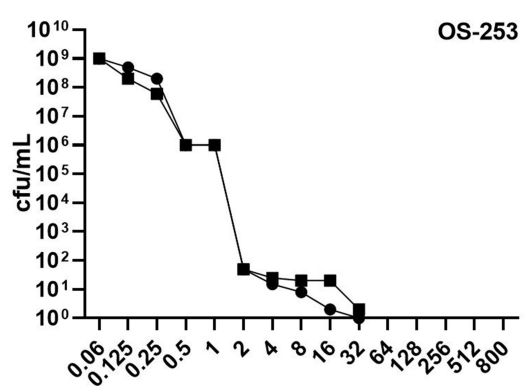

Oxacillin $(\mu \mathrm{g} / \mathrm{mL})$

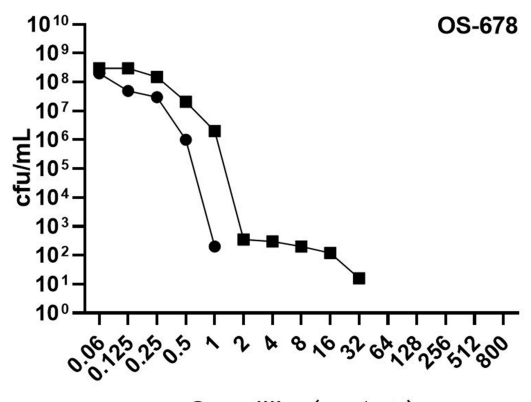

Oxacillin $(\mu \mathrm{g} / \mathrm{mL})$

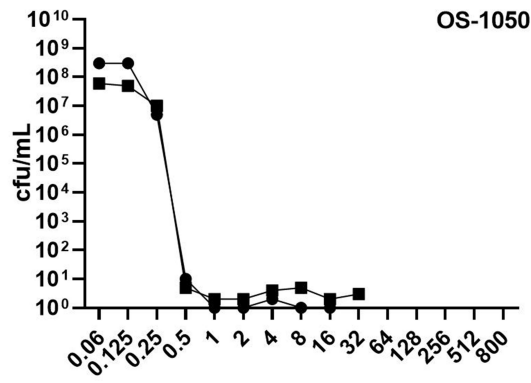

Oxacillin $(\mu \mathrm{g} / \mathrm{mL})$

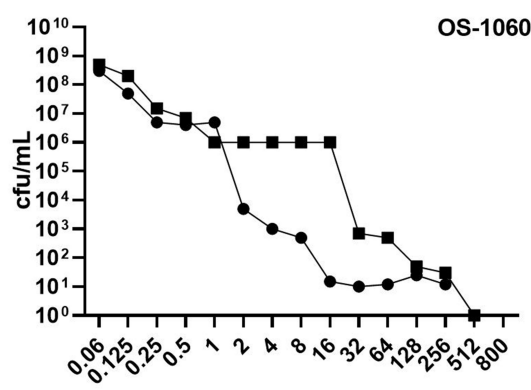

Oxacillin $(\mu \mathrm{g} / \mathrm{mL})$

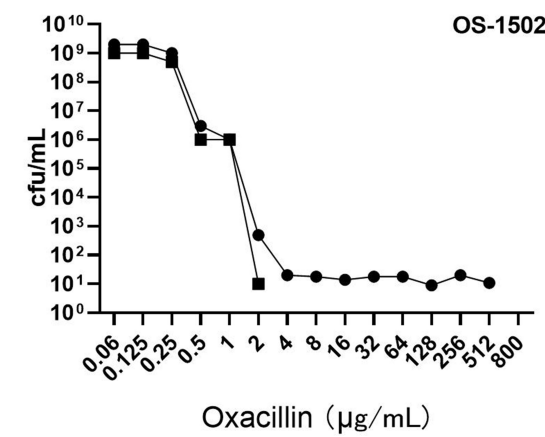

OS-373

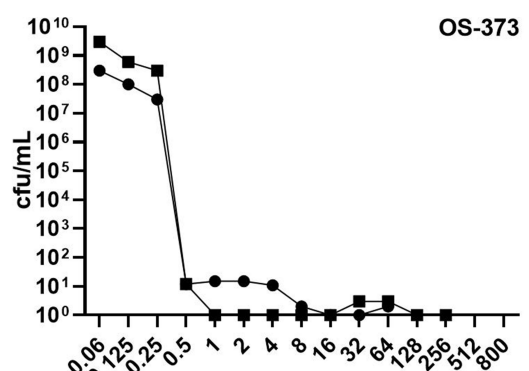

Oxacillin $(\mu \mathrm{g} / \mathrm{mL})$

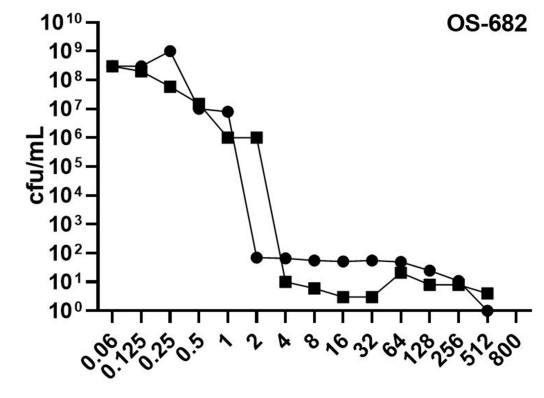

Oxacillin $(\mu \mathrm{g} / \mathrm{mL})$

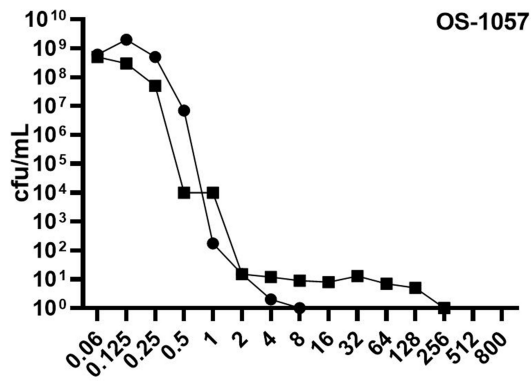

Oxacillin $(\mu \mathrm{g} / \mathrm{mL})$

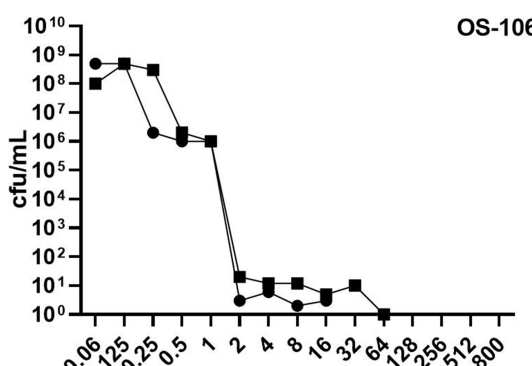

Oxacillin $(\mu \mathrm{g} / \mathrm{mL})$

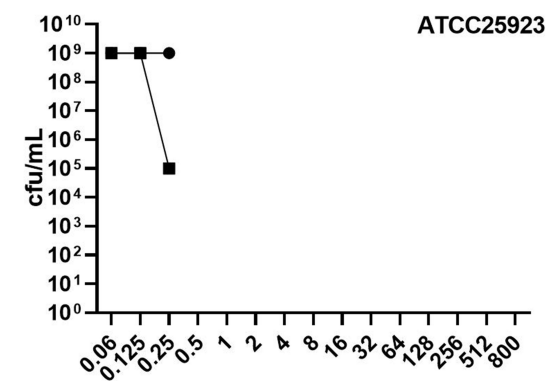

Oxacillin $(\mu \mathrm{g} / \mathrm{mL})$

Figure 2 Population analysis profiles of 14 OS-MRSA, I MRSA isolate and I MSSA isolate. •, oxacillin; $\mathbf{m}$, oxacillin+mupirocin. 
Table 4 Frequency of Heterogeneous Resistance and Expression of PBP2a Protein of 14 OS-MRSA Isolates

\begin{tabular}{|c|c|c|c|c|c|c|c|c|c|}
\hline \multirow[t]{2}{*}{ Isolate } & \multicolumn{3}{|c|}{ Primary Isolate } & \multicolumn{3}{|c|}{$\begin{array}{l}\text { Highly Oxacillin-Resistant } \\
\text { Subpopulations }{ }^{\text {b }}\end{array}$} & \multicolumn{3}{|c|}{$\begin{array}{l}\text { Highly Oxacillin-Resistant } \\
\text { Subpopulations }{ }^{c}\end{array}$} \\
\hline & $\begin{array}{l}\text { Oxacillin MIC } \\
\qquad(\mu \mathrm{g} / \mathrm{mL})\end{array}$ & PBP2a & Frequency ${ }^{\mathrm{a}}$ & $\begin{array}{l}\text { Oxacillin MIC } \\
\qquad(\mu \mathrm{g} / \mathrm{mL})\end{array}$ & Frequency & PBP2a & $\begin{array}{l}\text { Oxacillin MIC } \\
(\mu \mathrm{g} / \mathrm{mL})\end{array}$ & Frequency & PBP2a \\
\hline OS-200 & 1.0 & - & $10^{-5}$ & 64 & $10^{-9}$ & + & 128 & $10^{-9}$ & + \\
\hline OS-253 & 1.0 & + & $10^{-8}$ & 16 & $10^{-9}$ & + & 32 & $10^{-9}$ & + \\
\hline OS-373 & 0.25 & - & $10^{-8}$ & 64 & $10^{-8}$ & + & 256 & $10^{-9}$ & + \\
\hline OS-5II & 0.5 & + & $10^{-7}$ & 256 & $10^{-9}$ & + & 256 & $10^{-9}$ & + \\
\hline OS-678 & 0.5 & + & $10^{-7}$ & 256 & $10^{-9}$ & + & 32 & $10^{-8}$ & + \\
\hline OS-682 & 0.5 & - & $10^{-8}$ & 512 & $10^{-9}$ & + & 512 & $10^{-8}$ & + \\
\hline OS-790 & 0.25 & - & $10^{-9}$ & 4 & $10^{-9}$ & + & 128 & $10^{-9}$ & + \\
\hline OS- 1050 & 0.25 & + & $10^{-9}$ & 16 & $10^{-9}$ & + & 32 & $10^{-9}$ & + \\
\hline OS- 1057 & 0.5 & + & $10^{-5}$ & 128 & $10^{-9}$ & + & 256 & $10^{-9}$ & + \\
\hline OS- 1059 & 0.25 & - & $10^{-8}$ & 256 & $10^{-8}$ & + & 512 & $10^{-9}$ & + \\
\hline OS- 1060 & 0.25 & - & $10^{-6}$ & 256 & $10^{-9}$ & + & 512 & $10^{-9}$ & + \\
\hline OS-1061 & 0.5 & - & $10^{-9}$ & 16 & $10^{-9}$ & + & 64 & $10^{-9}$ & + \\
\hline OS- 1068 & 1.0 & - & $10^{-8}$ & 256 & $10^{-8}$ & + & 512 & $10^{-9}$ & + \\
\hline OS- 1502 & 0.5 & + & $10^{-8}$ & 512 & $10^{-8}$ & + & 4 & $10^{-9}$ & + \\
\hline
\end{tabular}

Notes: ${ }^{a}$ Oxacillin resistant subpopulations $(\geq 4 \mu \mathrm{g} / \mathrm{mL})$ screened by PAP method (serial oxacillin); ${ }^{\mathrm{b}}$ The subpopulations with the highest resistant level to oxacillin by PAP (serial oxacillin); 'The subpopulations with the highest resistant level to oxacillin by PAP (serial oxacillin plus $0.03 \mu g / \mathrm{mL} \mathrm{mupirocin}$ ).

belonged to SCCmec IV type, which was closely correlated with prevalent CA-MRSA strains, including ST59, ST15 and ST25 genotypes. ${ }^{7,23}$ In contrast to a recent report from China, no dominant clone was found among 14 OS-MRSA isolates in this study and only ST22-t309 clone accounted for $14.29 \%(2 / 14)$. At the same time, ST22 was also reported to be a predominant clone among community-acquired infections. ${ }^{24}$ Notably, the prevalence of $p v l$ gene among 14 OS-MRSA isolates was high up to $64.29 \%(9 / 14)$ and significantly higher than those reported in two studies from China, ${ }^{7,22}$ which was deemed to be closely correlated with enhanced virulence potential of CA-MRSA. ${ }^{25}$ Also, the majority of the isolates were isolated from the wound, pus, and blood samples, and only one isolate from sputum. The virulence potential of OS-MRSA should be paid more attention to.

In this study, a significant feature of OS-MRSA is its lower level of oxacillin resistance, when oxacillin MICs of the isolates are between $0.25 \mu \mathrm{g} / \mathrm{mL}$ to $1 \mu \mathrm{g} / \mathrm{mL}$. Consistent with the result reported by Liu et al, ${ }^{7}$ cefoxitin disc diffusion method showed better sensitivity in the identification of OS-MRSA in this study and $21.43 \%$ (3/14) were classified into MRSA, while both VITEK-2 and BD phoenix-100 ${ }^{\mathrm{TM}}$ misidentified all of the 14 OS-MRSA isolates as MSSA. Moreover, another significant feature of the 14 OS-MRSA isolates was the low-level expression of PBP2a protein, and only six isolates were positive with PBP2a protein using agglutination assay. In contrast, all of the tested OS-MRSA isolates were positive with PBP2a protein in two previous studies. ${ }^{7,8}$ On the contrary, all of the 14 OS-MRSA isolates were positive with the mecA gene. Based on the results of this study and some previous investigations, to accurately identify OS-MRSA and better treat its infections, the following suggestions were recommended. Firstly, for the patients with severe S.aureus infection and receiving $\beta$-lactam therapy for assumed MSSA with the phenotypic method, the mec $A$ and mec $C$ gene detection should be taken into account when the outcome of treatment is not ideal or even worsen. It is strongly recommended to communicate with laboratories about this issue, especially for the cases with oxacillin MICs $\geq 0.5 \mu \mathrm{g} / \mathrm{mL}$, since oxacillin MICs of most of the OS-MRSA isolates ranged from 0.5 to $2.0 \mu \mathrm{g} / \mathrm{mL}$ based on the results of this study as well as some previous studies. $7,8,22$ Secondly, the total resistance rates of 14 OS-MRSA isolates to several commonly tested antimicrobials were lower than 50\% except for penicillin, erythromycin, and tetracycline, which was consistent with a recent report by Liu et al. ${ }^{7}$ The clinician should consider non- $\beta$-lactam antimicrobials for severe $S$. aureus infection when the phenotypic method cannot be performed promptly. Finally, cefoxitin disk method is recommended to be carried out routinely to provide more accurate antibiotic susceptibility results for severe $S$. aureus infection, since this phenotypic method was shown to be with 
more detection sensitivity in discrimination of OS-MRSA. ${ }^{7}$ Alternatively, the laboratories should communicate on this issue with clinicians and seek help from other laboratories to perform genetic detection.

Inspired by a previous study, ${ }^{8}$ we further investigated the heterogeneous resistance feature of the 14 OS-MRSA isolates. We found it is universal among OS-MRSA isolates identified in this study. The frequency of oxacillin-resistant subpopulations among different isolates varied considerably from $10^{-9}$ to $10^{-5}$ and lower than those reported by Chung et al. ${ }^{8}$ However, highly resistant subpopulations with oxacillin MICs exceeding $100 \mu \mathrm{g} / \mathrm{mL}$ existed in $57.14 \%$ (8/14) OS-MRSA isolates by the PAP method. It is revealed that sub-inhibitory concentrations of $\beta$-lactam antibiotics could promote biofilm formation of OS$\mathrm{MRSA}^{26}$ and exposure to $0.5 \mathrm{MIC}$ of oxacillin, facilitating the conversion of OS-MRSA into highly resistant ones. ${ }^{7}$ When OS-MRSA was misinterpreted as MSSA using routine phenotypic methods and the patients were treated with $\beta$-lactam antibiotics, the highly resistant subpopulations are most likely to be selected and may lead to failure of treatment. How to rapidly and accurately identify OS-MRSA isolates with heterogeneous resistance feature seems to be more critical. Some novel techniques on a single-cell level may provide more choices to rapidly detect heteroresistance, such as droplet digital $\mathrm{PCR}^{27}$ and plasmonic colloidosomes coupled MALDITOF MS technique. ${ }^{28}$ Moreover, heterogeneously resistant clones could convert into homogeneously and highly resistant ones when exposed to mupirocin, which is well recognized as an effective inducer of the stringent stress response. ${ }^{29}$ In this study, $0.03 \mu \mathrm{g} / \mathrm{mL}$ mupirocin could significantly increase resistance levels of 10 OS-MRSA isolates to oxacillin at least two folds. In contrast, that of one isolate decreased (OS-1502). A similar phenomenon was reported by Chung et $\mathrm{al}^{8}$ and the mechanism of diverse responses of OS-MRSA to mupirocin needs to be further investigated.

Although this investigation revealed some new features of OS-MRSA, there are still some limitations in this study. Only 14 OS-MRSA isolates were detected from two hospitals, and a larger number of isolates should be collected from more hospitals. More detailed information about OS-MRSA may be more apparent to us. Owing to the limitation of expenditure, only the molecular typing features of 14 OS-MRSA isolates were investigated in this study, while those of the remaining 1186 non-OSMRSA isolates were not further explored, which deserves to be further investigated. Furthermore, some molecular mechanisms were reported to be correlated with the occurrence and heteroresistance of OS-MRSA, such as point mutations within the mec $A$ promoter, ${ }^{7}$ et al It was not investigated in this study, which is still under investigation in our laboratory.

In conclusion, 14 OS-MRSA isolates showed a significant clonal and resistance diversity. All of them were wrongly identified as MSSA with several phenotypic resistance detection methods that were widely applied in many clinical laboratories. The universal heterogeneous resistance of OS-MRSA observed in this study poses a more knotty issue for accurate identification and treatment of infections caused by OS-MRSA.

\section{Acknowledgments}

This study was supported by the National Natural Science Foundation of China (No.81260244, 81660352), Natural Science Foundation of Inner Mongolia Autonomous Region of China (Grant no. 2020MS08110), Affiliated hospital of Inner Mongolia Medical University (No, NYFY ZD 012), Graduate initiative program of Inner Mongolian Medical University (No, FYQMJH2020006) and Program for Young Talents of Science and Technology in Universities of Inner Mongolia Autonomous Region (No. NJYT-17-B06).

Roushan Liu and Jian Zhang contributed equally to this manuscript.

\section{Disclosure}

The authors declare that they have no conflicts of interest for this work.

\section{References}

1. Woodford N, Livermore DM. Infections caused by Gram-positive bacteria: a review of the global challenge. $J$ Infect. 2009;59(Suppl 1):S4-16. doi:10.1016/S0163-4453(09)60003-7

2. Schito GC. The importance of the development of antibiotic resistance in Staphylococcus aureus. Clin Microbiol Infect. 2006;12(Suppl 1):3-8. doi:10.1111/j.1469-0691.2006.01343.x

3. Peacock SJ, Paterson GK. Mechanisms of methicillin resistance in Staphylococcus aureus. Annu Rev Biochem. 2015;84(1):577-601. doi:10.1146/annurev-biochem-060614-034516

4. Bignardi GE, Woodford N, Chapman A, Johnson AP, Speller DC. Detection of the mec-A gene and phenotypic detection of resistance in Staphylococcus aureus isolates with borderline or low-level methicillin resistance. $J$ Antimicrob Chemother. 1996;37(1):53-63. doi:10.1093/jac/37.1.53

5. Sharff KA, Monecke S, Slaughter S, et al. Genotypic resistance testing creates new treatment challenges: two cases of oxacillin-susceptible methicillin-resistant Staphylococcus aureus. J Clin Microbiol. 2012;50 (12):4151-4153. doi:10.1128/JCM.01564-12

6. Hososaka Y, Hanaki H, Endo $\mathrm{H}$, et al. Characterization of oxacillin-susceptible mecA positive Staphylococcus aureus: a new type of MRSA. J Infect Chemother. 2007;13(2):79-86. doi:10.1007/ s10156-006-0502-7 
7. Liu JL, Li TM, Zhong N, et al. Current status of oxacillin-susceptible mecA positive Staphylococcus aureus infection in Shanghai, China: a multi-center study. J Microbiol Immunol Infect. 2020. doi:10.1016/j. jmii.2020.07.021

8. Chung M, Kim CK, Conceição T, et al. Heterogeneous oxacillin-resistant phenotypes and production of PBP2A by oxacillin-susceptible/mecApositive MRSAA strains from Africa. J Antimicrob Chemother. 2016;71 (10):2804-2809. doi:10.1093/jac/dkw209

9. Garci'a-A'lvarez L, Holden MT, Lindsay H, et al. Meticillin-resistant Staphylococcus aureus with a novel mecA homologue in human and bovine populations in the UK and Denmark: a descriptive study. Lancet Infect Dis. 2011;11(8):595-603. doi:10.1016/S1473-3099(11)70126-8

10. Paterson GK, Morgan FJE, Harrison EM, et al. Prevalence and characterization of human mecC methicillin-resistant Staphylococcus aureus isolates in England. $J$ Antimicrob Chemother. 2014;69(4):907-910. doi:10.1093/jac/dkt462

11. Duarte FC, Danelli T, Tavares ER, et al. Fatal sepsis caused by mecA-positive oxacillin-susceptible Staphylococcus aureus: first report in a tertiary hospital of southern Brazil. J Infect Chemother. 2019;25(4):293-297. doi:10.1016/j.jiac.2018.09.010

12. Monday SR, Bohach GA. Use of multiplex PCR to detect classical and newly described pyrogenic toxin genes in Staphylococcal isolates. J Clin Microbiol. 1999;37(10):3411-3414. doi:10.1128/ JCM.37.10.3411-3414.1999

13. Cikman A, Aydin M, Gulhan B, et al. Absence of the mecC gene in methicillin-resistant Staphylococcus aureus isolated from various clinical samples: the first multi-centered study in Turkey. $J$ Infect Public Health. 2019;12(4):528-533. doi:10.1016/j.jiph.2019.01.063

14. Stegger M, Andersen PS, Kearns A, et al. Rapid detection, differentiation and typing of methicillin-resistant Staphylococcus aureus harbouring either mecA or the new mecA homologue mecALGA251. Clin Microbiol Infect. 2012;18(4):395-400. doi:10.1111/j.14690691.2011.03715.x

15. McClure JA, Conly JM, Lau V, et al. Novel multiplex PCR assay for detection of the staphylococcal virulence marker panton-valentine leukocidin genes and simultaneous discrimination of methicillin-susceptible from -resistant staphylococci. J Clin Microbiol. 2006;44(3):1141-1144. doi:10.1128/JCM.44.3.1141-1144.2006

16. Mellmann A, Friedrich AW, Rosenkötter N, et al. Automated DNA sequence-based early warning system for the detection of methicillin-resistant staphylococcus aureus outbreaks. Plos Med. 2006;3(3):e33. doi:10.1371/journal.pmed.0030033

17. Wayne P. Performance Standards for Antimicrobial Susceptibility Testing. 29th ed. Clinical and Laboratory Standards Institute, CLSI supplement M100S; 2019.

18. Enright MC, Day NP, Davies CE, Peacock SJ, Spratt BG. Multilocus sequence typing for characterization of methicillin-resistant and methicillin-susceptible clones of Staphylococcus aureus. $J$ Clin Microbiol. 2000;38(3):1008-1015. doi:10.1128/JCM.38.3.10081015.2000
19. Zhang K, McClure JA, Elsayed S, Louie T, Conly JM. Novel multiplex PCR assay for characterization and concomitant subtyping of staphylococcal cassette chromosome mec types $\mathrm{I}$ to $\mathrm{V}$ in methicillin-resistant Staphylococcus aureus. J Clin Microbiol. 2005;43(10):5026-5033. doi:10.1128/JCM.43.10.5026-5033.2005

20. Tomasz A, Nachman S, LeafH. Stable classes of phenotypic expression in methicillin-resistant clinical isolates of staphylococci. Antimicrob Agents Chemother. 1991;35(1):124-129. doi:10.1128/aac.35.1.124

21. Andrade-Figueiredo M, Leal-Balbino TC. Clonal diversity and epidemiological characteristics of Staphylococcus aureus: high prevalence of oxacillin-susceptible mecA-positive Staphylococcus aureus (OS-MRSA) associated with clinical isolates in Brazil. BMC Microbiol. 2016;16(1):115. doi:10.1186/s12866-016-0733-4

22. Song YJ, Cui LQ, Lv Y, Li Y, Xue F. Characterisation of clinical isolates of oxacillin-susceptible mecA positive Staphylococcus aureus in China from 2009 to 2014. J Glob Antimicrob Resist. 2017;11:1-3. doi:10.1016/j.jgar.2017.05.009

23. Wang X, Shen YY, Huang WC, Zhou Y. Characterisation of community-acquired Staphylococcus aureus causing skin and soft tissue infections in a children's hospital in Shanghai, China. Epidemiol Infect. 2019;147:e323. doi:10.1017/S0950268819002127

24. Xiao N, Yang JH, Ning Duan N, Lu BH, Wang LJ. Communityassociated Staphylococcus aureus PVL+ ST22 predominates in skin and soft tissue infections in Beijing, China. Infect Drug Resist. 2019;12:2495-2503. doi:10.2147/IDR.S212358

25. Trista A, Bes M, Meugnier H, et al. Global distribution of pantonvalentine leukocidin-positive methicillin-resistant Staphylococcus aureus, 2006. Emerg Infect Dis. 2007;13:594e600. doi:10.3201/ eid1304.061316

26. He X, Li S, Yin Y, et al. Membrane vesicles are the dominant structural components of ceftazidime-induced biofilm formation in an oxacillin-sensitive MRSA. Front Microbiol. 2019;10:571. doi:10.3389/fmicb.2019.00571

27. Sun L, Talarico S, Yao L, et al. Droplet digital PCR detection of Helicobacter pylori clarithromycin resistance reveals frequent heteroresistance. J Clin Microbiol. 2018;56(9):e0019-18. doi:10.1128/JCM.00019-18

28. Dai Y, Li C, Yi J, Qin Q, Liu B, Qiao L. Plasmonic colloidosomes coupled with MALDI-TOF MS technique. Plasmonic colloidosome-coupled MALDI-TOF MS for bacterial heteroresistance study at single-cell level. Anal Chem. 2020;92 (12):8051-8057. doi:10.1021/acs.analchem.0c00494

29. Kim C, Mwangi M, Chung M, Milheiriço C, de Lencastre H, Tomasz A. The mechanism of heterogeneous beta-lactam resistance in MRSA: key role of the stringent stress response. PLoS One. 2013;8(12):e82814. doi:10.1371/journal.pone.0082814
Infection and Drug Resistance

\section{Publish your work in this journal}

Infection and Drug Resistance is an international, peer-reviewed openaccess journal that focuses on the optimal treatment of infection (bacterial, fungal and viral) and the development and institution of preventive strategies to minimize the development and spread of resistance. The journal is specifically concerned with the epidemiology of antibiotic resistance and the mechanisms of resistance development and diffusion in both hospitals and the community. The manuscript management system is completely online and includes a very quick and fair peerreview system, which is all easy to use. Visit http://www.dovepress.com/ testimonials.php to read real quotes from published authors. 